EGU21-14122, updated on 27 May 2021

https://doi.org/10.5194/egusphere-egu21-14122

EGU General Assembly 2021

(c) Author(s) 2021. This work is distributed under

the Creative Commons Attribution 4.0 License.

\title{
Planetary Cartography: Challenges for Mapping and Research Data Management
}

\author{
Andrea Nass ${ }^{1}$, Stephan van Gasselt ${ }^{2}$, Alessandro Frigeri ${ }^{3}$, Angelo Pio Rossi ${ }^{4}$, and Valentina \\ Galluzzi ${ }^{3}$ \\ ${ }^{1}$ DLR / Institut of Planetary Research, Planetary Geology, Berlin, Germany (andrea.nass@dlr.de) \\ ${ }^{2}$ National Chengchi University, Taipei, Taiwan \\ ${ }^{3}$ Instituto di Astrofisica e Planetologia Spaziali (INAF), Rome, Italy \\ ${ }^{4}$ Jacobs University Bremen, Department of Physics and Earth Sciences, 28759 Bremen, Germany
}

The aim of this contribution is to summarize recent activities in the field of Planetary Cartography by highlighting current issues the community is facing, and by discussing future research and development opportunities.

For this contribution we focus on (1) identifying and prioritizing needs of the planetary cartography community and the possible projected timeline to address these needs, (2) updating on ongoing work and activities in the field of planetary cartography across the globe, and (3) identifying areas of evolving technologies and innovations that could become interesting for the community in the planetary mapping sciences. The topics and discussion presented here also summarize outcome from community discussions and activities over the last years (e.g. [1-10]), and continue the initial discussion we have had during the last successful EGU session on Planetary Cartography and GIS in 2020.

In particular we would like to extend our discussion and put additional emphasis on aspects of map data re-use and research data management as well as on geodetic aspects of irregular bodies that will be target of future mission programs. We would like to invite cartographers, researchers and map-enthusiasts to join this community and to start thinking about how we can jointly solve some of these challenges.

[1] Di, K. et al (2020) Topographic mapping of the Moon in the 21th century: From hectometer to millimeter scales. The International Archives of the Photogrammetry, Remote Sensing and Spatial Information Sciences, Volume XLIII-B3-2020, doi:10.5194/isprs-archives-XLIII-B3-2020-1117-2020.

[2] Hargitai, H. et al (2019) Chinese and Russian Language Equivalents of the IAU Gazetteer of Planetary Nomenclature: an Overview of Planetary Toponym Localization Methods, The Cartographic Journal, 56:4, 335-354, doi:10.1179/1743277413Y.0000000051.

[3] Laura, J.R. et al (2017) Towards a planetary spatial data infrastructure. ISPRS Journal of GeoInformation 6, 181.

[4] Naß, A. et al (2019) Status and future developments in planetary cartography

and mapping. In: Wu et. al. (ed.) Planetary Remote Sensing and Mapping, Taylor \& Francis Group, 
London, ISBN 978-1-138-58415-0.

[5] Naß, A. et al (2020), GMAP Standard definition Document, 1st iteration, Europlanet H2024-RI deliverable, available at https://www.europlanet-gmap.eu/about-gmap/deliverables/.

[6] Naß, A. et al (submitted) Facilitating Reuse of Planetary Spatial Research Data - Conceptualizing an Open Map Repository as Part of a Planetary Research Data Infrastructure. Planetary and Space Science.

[7] Paganelli, F. et al (2020) The Need for Recommendations in Support of Planetary Bodies Cartographic Coordinates and Rotational Elements Standards, submitted to the Planetary Science and Astrobiology Decadal Survey White Paper 2023-2032.

[8] Radebaugh, J. et al (2020) Maximizing the Value of Solar System Data through Planetary Spatial Data Infrastructures, white paper submitted to the 2023-2032 Planetary Science and Astrobiology Decadal Survey.

[9] Semenzato, A. et al (2020) An Integrated Geologic Map of the Rembrandt Basin, on Mercury, as a Starting Point for Stratigraphic Analysis. Remote Sensing, 12(19), p.3213.

[10] Skinner, J.A. Jr. et al (2019) Planetary geologic mapping-program status and future needs. U.S. Geological Survey Open-File Report 2019-1012, 40 p., doi:10.3133/ofr20191012. 